A. Klimczuk, Creative Aging, Drawing on the Arts to Enhance Healthy Aging, [in:] N.A. Pachana (ed.), Encyclopedia of Geropsychology, Springer Singapore, Singapore 2016, pp. 608-612.

https://doi.org/10.1007/978-981-287-080-3 363-1

\title{
Creative Aging: Drawing on the Arts to Enhance Healthy Aging
}

Andrzej Klimczuk

Warsaw School of Economics, Warsaw, Poland

\section{Definitions}

The term "creative aging," in the broadest sense, describes an aging policy idea that focuses on highlighting the creativity of older adults in order to prepare individuals and communities to manage old age. Programs focus on the evolution of creativity over the lifespan and aim to provide meaningful participatory engagement, especially through the arts.

\section{A General History of the Creative Aging Movement and Best Practices}

The history of professionally-led creative aging programs may be traced back to the origins of the constructs of successful aging and healthy aging. These gerontological concepts were developed in the $1960 \mathrm{~s}$ in opposition to the prevailing construct at that time, namely disengagement theory. At the same time, aging interest groups emerged, which promoted cultural and lifestyle issues for older adults.

Some of the well-known creative aging programs started in the 1970s in the United States (USA) with combining art and activities for older adults. These programs were led by professional artists, such as Susan Perlstein (the founder of Elders Share the Arts) and Liz Lerman (the founder of the Dance Exchange). Also, organizations such as the Society for the Arts in Healthcare, founded in 1990, and Generations United, established in 1986, began various activities and programs related to the creativity of older adults in the context of health care, intergenerational programs, and public policies.

Cutler (2009) describes the creative aging movement also emerging in Europe in the 1970s. However, at that time, similar early initiatives related to the arts and aging were usually described as part of the community arts movement. Examples in the United Kingdom (UK) include the Plymouth Arts Centre and community arts funding initiatives of the Calouste Gulbenkian UK Trust. More specialized programs emerged in the 1980s, such as the Age Exchange (a center of reminiscence and intergenerational arts). Moreover, in Europe, various initiatives were (and still are) established through the Universities of the Third Age movement, such as courses, workshops, and debates focused on the arts and humanities.

In recent years, the creative aging movement became widespread around the world. There is a growing diversity of activities, but the arts remain at the core of initiatives. In the USA in 
A. Klimczuk, Creative Aging, Drawing on the Arts to Enhance Healthy Aging, [in:] N.A. Pachana (ed.), Encyclopedia of Geropsychology, Springer Singapore, Singapore 2016, pp. 608-612.

https://doi.org/10.1007/978-981-287-080-3 363-1

2001, Gene Cohen and Susan Perlstein established one of the best-known such organizations, the National Center for Creative Aging (NCCA) by, building a partnership with the National Council on Aging and the National Endowment for the Arts (NEA), in affiliation with George Washington University. The organization advocates on issues concerning the arts and aging, promotes combining of the arts and aging policy, organizes events and conferences, provides training and e-learning courses and toolkits, and maintains databases of resources and best practices.

\section{Creative Aging Programs}

Creative aging programs aim to foster older persons' social engagement, skills, and opportunities for creative expression ("Creative Aging Toolkit for Public Libraries" (2016)). Three forms of creative aging practice include: (1) health and wellness programs (e.g., use of art therapies in institutionalized settings for older adults with dementia); (2) community engagement programs that focus on civic involvement of older people through the arts (e.g., volunteering, mentoring, and intergenerational programs); and (3) lifelong learning (LLL) programs that aim to improve the quality of life of older adults by building skills during various courses. Thus, creative aging programs are not simply synonymous with art workshops for seniors and tend to be delivered by professionals in diverse settings (e.g., long-term care facilities, public libraries, senior centers, and non-governmental organizations that focus on education, culture, heritage, and socialization).

Creative aging programs may also be considered as examples of new healthcare services that deliver enjoyable and fun activities in safe environments. As Hanna and Perlstein (2008) argue, creative aging may also provide a new perspective that encourages and promotes the potential (capital) of older adults rather than emphasizing their problems. To achieve this, creative aging programs should be aimed at increasing morale and passing on a legacy to younger and future generations of older adults as a means of sustaining the culture (a cultural and symbolic capital), improving physical health (human capital), and building relationships (social capital). In other words, such programs provide the basis to foster the empowerment of older adults by the promotion of emancipation or social justice, democratic citizenship, and human capital (Payne 2012).

\section{Creative Caregiving}

Creative caregiving techniques and exercises mainly draw on creative and art therapies to 
A. Klimczuk, Creative Aging, Drawing on the Arts to Enhance Healthy Aging, [in:] N.A. Pachana (ed.), Encyclopedia of Geropsychology, Springer Singapore, Singapore 2016, pp. 608-612.

https://doi.org/10.1007/978-981-287-080-3 363-1

enhance the quality of life in both older people and caregivers, the latter including both informal (e.g., family) and professional caregivers ("NCCA Creative Caregiving Guide" 2016). In addition to the arts, creative approaches can draw on culture, science, business, and technology. Artistic creativity, for example, involves exploring new ways of interpreting the world that can produce texts, sounds, and images in response to stimulating thought-provoking questions. Creativity can also result from innovation and design. The innovation may involve the translation of ideas into new products, services, management models, or social processes. The design includes processes integrating creativity and innovation, leading to useful solutions in a caregiving context. Creative caregiving is congruent with "older-person-centered and integrated care" promoted by the World Health Organization (2015).

\section{Creative Aging Policy}

Creative aging policy can be used both as theories (descriptive models) and as ideologies or strategies (normative models) that provide frameworks for constructing positive responses to population aging. This form of policy is typically considered in the context of other aging policies ideas such as successful aging, productive aging, healthy aging, active aging, positive aging, aging in place, and intergenerational policy.

Creative aging policy aims to engage older adults in creative activity and involves a shift away from highlighting problems of aging to promoting the potential of older adults (Klimczuk 2015). It focuses on providing opportunities, technological innovations (gerontechnologies), and social innovations for all older adults, not only those who have had careers within cultural and creative industries. It supports a creative approach to leisure time in old age, regardless of whether the focus is on professional or amateur activities.

There is a complementarity of creative aging policy to the official United Nations active aging policy and thus to the related concept of healthy aging, both referred to in the 2002 "Madrid International Plan of Action on Ageing" (MIPAA). A “glocalization ” of policy ideas, that is, translating and implementing general policy ideas from international organizations' policies to the local level (cities and communities) and regional level, is also implied.

\section{Selected Theories and Research on Creativity and Aging}

There are two contrasting frameworks - the "peak and decline model" and the "lifespan developmental model" - that provide frameworks to understand creative aging as a means of 
A. Klimczuk, Creative Aging, Drawing on the Arts to Enhance Healthy Aging, [in:] N.A. Pachana (ed.), Encyclopedia of Geropsychology, Springer Singapore, Singapore 2016, pp. 608-612.

https://doi.org/10.1007/978-981-287-080-3 363-1

constructing positive responses to population aging.

The "peak and decline model" is based on the Western cultural definitions of creativity that highlight production, quantity, and novelty (Levy and Langer 1999). These features can be evaluated through the use of psychometric and productivity tests that usually lead to the conclusion that with age, people tend to lose their creative abilities. This model has been criticized for excessive attention to results from standardized tests of creativity, which may not tap creativity as it is expressed throughout the lifespan. In contrast, the "lifespan developmental model" (also known as the continuity model) relies more on the qualitative measurement of creativity, with a greater focus on mechanisms leading to growth, change, and the evolution of creativity over the lifespan (Reed 2005).

Research conducted by Gene D. Cohen is considered groundbreaking in the field of arts and aging. Cohen has focused on the development of the brain in old age and its relation to creativity. His studies explore the hypothesis that maintaining a high level of creativity in old age requires not only appropriate external stimulation but also the inner need to solve increasingly complex problems with the use of creativity, and that this leads to positive health outcomes.

According to Cohen (2009), creativity in old age may be presented as the creativity equation $(\mathrm{C}=\mathrm{me} 2)$. Here creativity $(\mathrm{C})$ may be seen as the result of one's mass (m) of knowledge, which is multiplied by the effects of one's two dimensions of experience (e2). These dimensions include an individual inner world experience (emotions and personality), and the outer world (experience and wisdom). From this perspective, aging has a positive influence on creativity due to the accumulation of knowledge and experience. Thus, the aging brain is still developing with new experiences and learning (Cohen 2001, 2005). These activities lead to the creation of new brain cells between our early 50s and late 70s. Thus, with proper stimulation and good health, further intellectual development is possible. Moreover, with age, brain functioning becomes more balanced in the areas responsible for emotions, and the brain's two hemispheres are more evenly used. These changes allow older people to be more creative.

Cohen and his team (2006) carried out a study of the impact of community-based cultural programs on the physical health, mental health, and social activities of older people (aged 65 and older). The research sample consisted of 166 older people from the region of Washington, DC. Participants were divided into two groups - an intervention (chorale program) and a comparison (usual activity) group. These groups were assisted by researchers at the beginning of the project, after 12 months, and after 24 months. The programs included artistic activities 
A. Klimczuk, Creative Aging, Drawing on the Arts to Enhance Healthy Aging, [in:] N.A. Pachana (ed.), Encyclopedia of Geropsychology, Springer Singapore, Singapore 2016, pp. 608-612.

https://doi.org/10.1007/978-981-287-080-3 363-1

such as painting, ceramics, dance, music, poetry, theater, and talks on material culture and spoken histories. The research demonstrated that the cultural program participants reported a better overall degree of physical health, fewer doctor visits, less medication usage, fewer falls, and fewer other health problems than the comparison group. Advantages in sociological terms were primarily better morale, increased activity, and less loneliness than the control group. In other words, the intervention helped in reducing the risk factors that may increase the necessity for long-term care services. This is potentially due to an increase in a sense of control and meaningful social engagement.

\section{Potential Personal and Societal Benefits of Creative Aging}

The literature about the arts and creative aging programs provides various examples of effects that may be achieved by the arts and creative expression intervention programs. For example, Moloney (2006) and Ehlert et al. (2010) proposed several groups of beneficiaries from such programs. First, older adults themselves may achieve personal fulfillment, a sense of meaning, new competencies to cope with daily challenges, new social relationships, and opportunities for maintaining and improving health. Second, organizations that are developing and implementing programs, particularly within the arts sector, may find benefits, including engagement of older artists, access to new audiences, the development of learning communities, and changes in program funding opportunities. Third, the health sector may benefit through increased health benefits for older adults, such as fewer visits to doctors and lower levels of depression (CastoraBinkley et al. 2010). Moreover, the engagement of older adults in creative activities in care settings may lead to increased quality of life for staff, improved retention of personnel, facilitation of points of communication for visitors, increased social cohesion, the development of volunteering, and the establishment of new programs of activities. Finally, benefits may also accrue to the general public. Positive outcomes include here the promotion of intergenerational solidarity, the development of positive older role models, the establishment of cooperation between different sectors of society, and the provision of new strategies to reach diverse groups of older adults.

\section{Conclusion and Future Directions}

In recent years, the dissemination of creative aging practices has appeared across the globe (Bloom 2014). However, at this point, barriers and challenges remain for the development of creative aging programs. These observations may be at the same time considered as potential 
A. Klimczuk, Creative Aging, Drawing on the Arts to Enhance Healthy Aging, [in:] N.A. Pachana (ed.), Encyclopedia of Geropsychology, Springer Singapore, Singapore 2016, pp. 608-612.

https://doi.org/10.1007/978-981-287-080-3 363-1

directions for further research.

One set of challenges concerns insufficient dissemination among the public and healthcare professionals about outcomes from arts and aging programs. In addition, there has been only limited development of standardized techniques for evaluating the use of the arts in healthcare programs and identifying best practices (e.g., Thomas and Lyles 2007). The use of the knowledge and skills of professional artists in engaging with older adults within the community and healthcare settings remains limited. Aside from creative aging's greatest advocate, Gene Cohen, there is the limited promotion of knowledge about the benefits of creative aging. There is a need for greater research efforts and a common language concerning creative aging. Finally, funding for interdisciplinary strategies in healthcare regarding the arts remains scarce.

\section{References}

Bloom, M. (2014). Creativity in older adults. In T. P. Gullotta \& M. Bloom (Eds.), Encyclopedia of primary prevention and health promotion (2nd ed., pp. 1933-1941). New York: Springer.

Castora-Binkley, M., Noelker, L., Prohaska, T., \& Satariano, W. (2010). Impact of arts participation on health outcomes for older adults. Journal of Aging, Humanities, and the Arts, 4(4), 352-367.

Cohen, G. D. (2001). Creativity with aging: Four phases of potential in the second half of life. Geriatrics, 56(4), $51-57$.

Cohen, G. D. (2005). The mature mind: The positive power of the aging brain. New York: Basic Books.

Cohen, G. D. (2009). Creativity, later life. In D. S. Carr (Ed.), Encyclopedia of the life course and human development. Vol. 3 later life (pp. 85-89). Detroit: Gale Cengage Learning/Macmillan Reference USA.

Cohen, G. D., Perlstein, S., Chapline, J., Kelly, J., Firth, K. M., \& Simmens, S. (2006). The impact of professionally conducted cultural programs on the physical health, mental health, and social functioning of older adults. Gerontologist, 46(6), 726-734.

Creative Aging Toolkit for Public Libraries. (2016). Retrieved from http://creativeagingtoolkit.org

Cutler, D. (2009). Ageing artfully: Older people and professional participatory arts in the UK. London: Baring Foundation.

Ehlert, A., Fricke, A., \& Marley, M. (2010). The increase guide: A manual about intercultural 
A. Klimczuk, Creative Aging, Drawing on the Arts to Enhance Healthy Aging, [in:] N.A. Pachana (ed.), Encyclopedia of Geropsychology, Springer Singapore, Singapore 2016, pp. 608-612.

https://doi.org/10.1007/978-981-287-080-3 363-1

creativity of older age. Badajoz/Glasgow/Remscheid/Wolfenbuttel: Increase Learning Partnership.

Hanna, G. P., \& Perlstein, S. (2008). Creativity matters: Arts and aging in America.

Washington, DC: Americans for the Arts.

Klimczuk, A. (2015). Economic foundations for creative ageing policy, volume I: Context and considerations. New York/Basingstoke: Palgrave Macmillan.

Levy, B., \& Langer, E. (1999). Aging. In M. A. Runco \& S. R. Pritzker (Eds.), Encyclopedia of creativity. volume 1 (pp. 45-52). San Diego: Academic.

Moloney, O. (2006). Age \& opportunity guidelines for working with older people in the arts: A resource for Bealtaine organisers and others involved in the arts and older people.

Dublin: Bealtaine Festival/Age \& Opportunity.

NCCA Creative Caregiving Guide. (2016). Retrieved from http://creativecaregiving.creativeaging.org

Payne, M. (2012). Citizenship social work with older people. Chicago: Lyceum Books.

Reed, I. C. (2005). Creativity: Self-perceptions over Time. The International Journal of Aging and Human Development, 60(1), 1 -18.

Thomas, J. E., \& Lyles, K. (2007). Creativity and aging: Best practices. Washington, DC: National Endowment for the Arts.

World Health Organization. (2015). World report on ageing and health. Geneva: World Health Organization. 